\title{
Untangling the Health Impacts of Mexico - U.S. Migration
}

\author{
DAVID L. ORTMEYER \\ Bentley University \\ MICHAEL A. QUINN \\ Bentley University*
}

\begin{abstract}
Research has found that immigrant health has a tendency to decline with time spent in the United States. Using data from the Mexican Migration Project from 2007-2014, this paper is the first to test the impact of domestic and international migration on different types of health measures. Results find cumulative U.S. migration experience has a negative impact both on self-reported and objective health measures. By contrast, the number of trips to the United States and migrations made within Mexico impact individual's self-assessment of their health but not objective health measures. The analyses suggest that differences in self-reported versus objective health measures may help to explain mixed results in the literature. Results suggest that individual's health will suffer considerably more from U.S. migrations than from migration within Mexico which is consistent with the acculturation hypothesis. Not surprisingly, high levels of BMI and smoking are significant predictors of negative self-reported and objective health. There is also a troubling significant negative trend in health over time observed in the sample. Taken as a whole, these results suggest that even short trips to the United States can have a negative health effect on immigrants if they are repeated.
\end{abstract}

Keywords: Mexico, migration, health, acculturation

JEL Classifications: O5, F22

\section{Introduction and Background}

Mexico-U.S. migration grew to become the world's largest bilateral migration flow. This has resulted in 13 million Mexicans living in the United States (Inkpen, 2014). The scale of this migration has impacted the overall immigrant profile of the United States, with almost $30 \%$ of the foreign born population in the United States being from Mexico (Passel, Cohn and Gonzalez-Barrera, 2012). There have been concerns over the potential health impact of such

\footnotetext{
*Coresponding author: mquinn@bentley.edu

(C) 2018 David L. Ortmeyer and Michael A. Quinn. Licensed under the Creative Commons Attribution - Noncommercial 3.0 Licence (http://creativecommons.org/licenses/by-nc/3.0/. Available at http: //rofea.org.
} 
large migration flows, both for the destination and source countries. In the United States, immigrant health care is a significant policy issue. The majority of immigrants from Mexico do not have health insurance and rely on emergency room care, which is expensive and inefficient (Edwards, 2010). While immigrants utilize fewer health services overall than native born individuals, their emergency room bills are, on average, three times higher than those of native born individuals (Mohanty et al, 2005). The aggregate costs of U.S. healthcare for illegal immigrants (many of whom are from Mexico) has been estimated at over $\$ 4$ billion per year (Edwards, 2010). Health care costs in Mexico have also risen substantially over the last couple of decades as the incidence of obesity and diabetes have become much closer to American levels. The rate of diabetes in Mexico and the United States have risen to 11.8 and 10.9 percent, respectively (International Diabetes Federation, 2014). This represents a significant increase in both countries, with diabetes rates having more than doubled over the last 20 years (CDC, 2012). In addition to the direct costs of care, diabetes has been shown to have indirect costs such as a negative impact on employment rates (Seuring, Goryakin, and Suhrcke, 2015).

The size of the bilateral migration flows between Mexico and the U.S. and the declining health of the migrants over time have served to focus research on the issue of immigrants and health. Studies have suggested that healthier people tend to be the ones to migrate (Chiswick, Lee and Miller, 2008; Jasso et al., 2004; Marmot, Adelstein and Bulusu, 1984; Tong and Piotrowski, 2012). Moreover, immigrants who do experience health problems often return and stay home (Arenas et al, 2015). Thus, the immigrants who migrate (especially internationally) and either remain or undergo repeat migrations will appear to be a healthier sample of individuals. This issue has been termed "salmon bias" in the literature (Palloni and Arias, 2004; Turro and Elo, 2008).

Related to this research has been the "healthy immigrant" effect, which finds that, controlling for socioeconomic status, immigrants tend to be healthier than comparable native born individuals. This has been found for several ethnic groups of immigrants in the United States and Canada (Ahmed, 2005; Deri, 2003; Frisbie, Cho and Hummer, 2001; McDonald and Kennedy, 2004). Of particular interest to this paper, is the substantial literature which has found support for this hypothesis among Latino immigrants in the United States (LeClere, Rogers and Peters, 1997; Marmot, Adelstein, and Bulusu, 1984; Jasso et al., 2004; Jasso et al., 2005; Antecol and Bedard, 2006). This has been termed as the "Hispanic health paradox" (Hummer et al, 2000; Markides and Eschbach, 2005; Palloni and Arias, 2004). A key component of the Hispanic health paradox is that immigrants are healthier when compared to native-born people of the same socioeconomic status (SES) rather than across SES. 


\section{ORTMEYER, QUINN Health Impacts of Mexico - U.S. Migration}

While immigrants may be healthier on arrival than comparable native born individuals, their health can decline with time spent in the destination country. Several studies have found that immigrants' health quality begins to converge to that of the native-born population over time (Antecol and Bedard, 2006; Chiswick, Lee and Miller, 2008; Cobas et al., 1996; Guendelman \& Abrams, 1994; Zsembik and Fennell, 2005). One explanation for this health convergence is acculturation. Acculturation posits that, over time, immigrants take on the lifestyle and dietary habits of native born individuals and this results in the immigrants' health decline (Arcia et al, 2001; Biddle, Kennedy and McDonald, 2007; Black and Markides, 1993; Markides, Krause and Mendes de Leon, 1988). Acculturation may be more prevalent for immigrants with lower levels of education ( $\mathrm{Li}$ and Hummer, 2015). However, the evidence in favor of the acculturation hypothesis is not universal (Jasso, 2004; Teitler, Hutto, and Reichman, 2012). In a relevant recent study using data from the Mexican Health and Aging Study, Riosmena, Wong, and Palloni (2013) did not find evidence of acculturation among Mexican immigrants aged 50 and above. The implications of the acculturation literature for this paper are that with increased migration from Mexico to the United States, migrants in the United States will experience a decline in health over time. If these migrants eventually return home to Mexico, they will be coming home with worsened health. The most common variable used to test the acculturation hypothesis is the cumulative amount of time spent in the host country.

There have also been debates in the literature regarding the type of health measures used in empirical studies. Some studies have focused on using self-reported health measures as the dependent variable (Riosmena, Wong, and Palloni, 2013; Arenas et al, 2015). Self-reported health variables have the advantage of being broad health measures rather than specific to any one particular condition. In addition, asymmetric information may exist where the individual knows more about their own health condition than do others. However, self-reported measures suffer from potential "perception" biases. Individuals may not be using the same measure for "good" or "fair" health and/or their migration experiences may change the standards by which they measure health (Bzostek, Goldman, Pebley, 2007; Finch et al, 2002; Molina, 2016). Objective health measures, such as the diagnosed existence of specific medical conditions are, on the other hand, not subject to self-interpretation and therefore more likely to be accurate indications of health status. However, they too suffer from possible disadvantages. For example, the response covers only the specific medical condition. Also, rates of diagnosis may vary by socioeconomic status. For all these reasons, the analyses in this paper will follow the example of Li and Hummer's (2015) study of Asian immigrants who moved to the United States by using both self-reported and objective health measures. 
Because we have data on both domestic and U.S. migration experience, we can assess their differential impacts on both subjective and objective health measures. The hypotheses explored in this paper are:

H1) The impact of migration within Mexico on self-reported and objective health measures is expected to be zero or slightly negative. Acculturation should be less relevant in this case (as compared to U.S. migration) but there still may be negative health impact from living and working away from their home community.

H2) The impact of migration to the U.S. on self-reported and objective health measures is expected to be more negative than for domestic migration.

H3.) Self-reported and objective health measures may not yield the same results.

H4.) Self-reported and objective health measures are expected to exhibit negative trends over time.

The first and second hypotheses refer to the differential impact of U.S. versus domestic migration. Acculturation is one reason to expect a more negative effect of U.S. migration on health. Another may be differences in people's self-reporting of health based on their U.S. migration experience and/or stress from the crossing. For the two objective health measures, it could also be that people with experience in the U.S. are either accessing medical care in the United States to get diagnosed and/or gaining additional information regarding these diseases which results in them seeking care when back in Mexico. Self-reported and objective health measures as dependent variables have yielded mixed results in the literature, so no strong prediction can be made for hypothesis three. The fourth hypothesis reflects an expected decline in health based on survey year, as generally rates of diabetes and hypertension have been rising in Mexico over time.

The next section describes the data set and variables. This is followed by an explanation of the logit and ordered logit methodologies used in the analysis. The paper then proceeds with a discussion of the results followed by their implications for the literature and policy.

\section{Data and Variables}

The data are taken from the Mexican Migration Project (MMP, 2015) which is run jointly by the University of Guadalajara and Princeton University. Each year, the MMP samples around 150-200 households from 3-5 non-repeating Mexican communities. The data set is crosssectional in the sense that it is collected across different communities in each year. It is also time-series in the sense that it is collected over time (but not for the same communities in each year). This data can thus be used to investigate hypotheses that are expected to vary across communities as well as over time. The data is grouped by community, by households within the communities and by individuals within the households. Variables are defined that 


\section{ORTMEYER, QUINN Health Impacts of Mexico - U.S. Migration}

are relevant to each data grouping. Interviewers collect a vast array of information about individuals who are present in the surveyed household and individuals who are not present because they have migrated to the U.S. or to destinations within Mexico.

Our interest is in the effect on health of the migration behavior of individuals. While the MMP started collecting data in 1984, health questions were asked only starting in 2007. However, our sample is still large at 3,574 individuals collected in surveys from 2007-2014. The MMP data contains detailed migration and health histories of these individuals, encompassing such information as the number of migrations to the U.S. and within Mexico, the cumulative time spent in the U.S., the overall current health of the individuals and how their health has changed over time, specific health conditions and various demographic information. The sample is restricted to male heads of household. There are so few female heads of household in the data that including them might confound the analysis. In addition, there is some research to suggest that male heads of household are more likely to engage in circular U.S. or domestic migration patterns than female migrants (Reyes, 2001). In our sample, $25 \%$ of individuals undertook at least one migration to the United States, $20 \%$ undertook at least one domestic migration, 5\% migrated to both the U.S. and within Mexico, and $60 \%$ did not migrate at all.

There are three health-related dependent variables used in the analysis. One is the perceived change in health of the individual. This is the individual's perceived change in health as compared to their health at age 14. Using health at age 14 as a baseline should help focus on the impact of migration and help control for some preexisting conditions. This is a subjective, self-reported measure of health. The other two measures are the diagnosed presence of hypertension in the individual and the diagnosis of diabetes.

The dependent variable reflecting the perceived change in health of the individual from age 14 was based on data collected between 2007 and 2014 across 27 Mexican communities. The data set contains two variables, one reflecting the quality of health of the individual at age 14 and one reflecting the current quality of health at the time of the survey. Each is an ordinal variable measured on a scale of 1 to 4 (poor, regular, good and excellent). The change in health variable is defined as the current quality of health minus the quality of health at age 14. ${ }^{1}$ If there is no perceived change in the level of health, the rank is zero. If health is currently better the rank is positive, ranging from 3 (most improved) to 1 (slightly improved). If health is currently worse the rank is negative, ranging from -3 (significantly worse) to -1 (slightly worse). In our sample, the observed values for change in health are from -3 to 1 .

The dichotomous dependent variables representing the presence of hypertension and diabetes were based on specific interview questions as to whether the subject has been

\footnotetext{
${ }^{1}$ The sample data show that only a small percentage (less than $1 \%$ ) of migrations occurred before age 14 and thus any effect on health of migrations would largely be captured by this variable.
} 
diagnosed with high blood pressure or diabetes or high sugar levels. A value of 1 indicates the individual has been diagnosed with the condition and a value of zero indicates that they have not. Diabetes and hypertension were chosen because they are conditions which are easily diagnosed. More importantly for the issue of acculturation, diabetes and hypertension are more closely linked to lifestyle factors than the other available health outcome variables such as cancer and strokes.

There are three explanatory variables regarding individuals' migration experience: the number of U.S. migrations, the number of domestic migrations, and cumulative migration experience in the United States. This last variable is measured in months and is of interest in assessing the effect on health of prolonged (or repeated) stays in the United States. Cumulative U.S. experience has been used as an empirical test of the acculturation hypothesis, as discussed in the literature review. The MMP does not collect data on cumulative migration experience within Mexico. With some analyses using both total number of U.S. trips and cumulative U.S. experience, multicollinearity can be a concern. The correlation between number of U.S. trips and cumulative U.S. experience is only .51. Also, a VIF (variance inflation factor) test was run and all the results were below critical values. There is a considerable variation in the duration of trips to the United States which is likely the reason for the lack of multicollinearity between these two variables.

There are a number of explanatory variables used in the analysis to control for life-style choices and background and community characteristics that could negatively impact health over time. These include background control variables such as age, age squared, and the educational level (measured in years completed) of the individual. Older individuals are likely to have more health issues. Better educated individuals are likely to have fewer long term health issues, although some conditions can increase with higher income levels (Doytch, Dave, and Kelly, 2016). Unhealthy life-style choices were captured by whether the individual currently smokes and the BMI of the individual as a measure of obesity. Control variables were included for property ownership by the household and the receipt of remittances from the United States.

The size of the migrant's home community in Mexico was captured by a series of dummy variables covering large city, small city, town, or rural area. The size of the community could impact the migrant's access to healthcare services in Mexico. Different aspects of economic development and migration networks can vary by community (Dolfin and Genicot, 2010; Kijima and Gonzalez-Ramirez, 2012). Therefore, errors were clustered based on community number in order to control for community level unobserved heterogeneity. Also included as a community control for access to health care is the number of doctor's offices in their home community in Mexico.

The health care access controls are based on the migrant's Mexican community as the information on their access to healthcare while they were in the United States is more limited. 
However, Mexican immigrants' access to the U.S. healthcare is often limited to emergency care. In the MMP data, $87 \%$ of the U.S. migrations were undocumented. Undocumented immigrants are not eligible to enroll in the U.S. federal government's Medicaid health care program. Even legal immigrants in the United States can encounter a five year waiting period before being able to enroll in Medicaid, depending on their state of residence. Access to employer provided private health insurance is less likely for unskilled workers overall in the United States and this is especially problematic for undocumented workers as they lack the necessary paperwork often required for enrollment. Undocumented migrants in the United States have very limited access to the health care system. With the vast majority of those in the sample currently living back in their home community in Mexico, the medical system in Mexico is a very important factor in their health.

Over the last two decades, Mexico has significantly increased access to health care, especially among households in poverty and/or living in rural areas. From 1995-2014, the public share of health expenditure rose from $42.1 \%$ to $51.8 \%$ (World Bank, 2018). While this is still low compared to many Western European countries, it is a significant increase in public health expenditures. The Mexican government has expanded health insurance coverage for poor households without private insurance through their Seguro Popular program. From 2009-2013, Seguro Popular had a major expansion increasing the number of individual beneficiaries from 31.1 million to 55.6 million (World Bank, 2015). However, as of 2013, out-of-pocket medical spending (as a share of total health spending) in Mexico was still the highest among OECD countries (OECD, 2015). This suggests that a significant coverage gap still exists in terms of Mexican households having access to either private or public health insurance schemes.

Table 1 contains summary statistics for the variables used in this paper.

\section{Empirical Methodology}

As discussed in the previous section, we utilize three dependent variables in our analysis. The first dependent variable, the change in health from age 14, is an ordinal variable where each observation is ranked in terms of degree. The other two objective health variables reflecting diagnosed hypertension and diabetes are dichotomous variables. Our interest with all three dependent variables lies is in predicting the probability of an improved or worsened health outcome as a function of such factors as number of domestic and U.S. migrations and the cumulative experience in the U.S., controlling for other factors. Hence, natural estimation techniques to use are ordered logistic regression for the ordinal dependent variable and logit regression for the dichotomous dependent variables. ${ }^{2}$ These regressions are run with standard errors clustered based on community number.

\footnotetext{
${ }^{2}$ This was estimated using the ologit, gologit2 and logit commands in Stata.
} 
Review of Economic Analysis 10 (2018) 151-179

Table 1: Descriptive Statistics

\begin{tabular}{|l|r|r|r|r|}
\hline Variable Name & Mean & Std. Dev. & Minimum & Maximum \\
\hline \hline Change in health since age 14 $<0$ & & & & \\
worse, $>0$ better) & -0.59 & 0.76 & -3.00 & 2.00 \\
Diabetes (=1 if yes) & 0.11 & 0.32 & 0.00 & 1.00 \\
Hypertension (=1 if yes) & 0.16 & 0.36 & 0.00 & 1.00 \\
Age (years) & 48.95 & 14.97 & 19.00 & 102.00 \\
Age Squared & 2619.92 & 1578.93 & 361.00 & 10404.00 \\
Education (years) & 7.51 & 4.39 & 0.00 & 22.00 \\
Number of U.S. Migrations & 0.54 & 1.49 & 0.00 & 26.00 \\
Cumulative U.S. Experience (months) & 20.64 & 61.17 & 0.00 & 768.00 \\
Number of Domestic Migrations & 0.33 & 0.89 & 0.00 & 17.00 \\
Smokes (=1 if yes) & 0.20 & 0.40 & 0.00 & 1.00 \\
Body Mass Index (BMI) & 27.32 & 4.01 & 14.34 & 61.27 \\
Own Property (=1 if yes) & 0.78 & 0.42 & 0.00 & 1.00 \\
Remittances (=1 if received by HH) & 0.11 & 0.32 & 0.00 & 1.00 \\
Number of Doctor Offices & 27.82 & 38.62 & 2.00 & 130.00 \\
Large Urban (=1 if yes) & 0.14 & 0.34 & 0.00 & 1.00 \\
Small Urban (=1 if yes) & 0.10 & 0.30 & 0.00 & 1.00 \\
Town (=1 if yes) & 0.68 & 0.47 & 0.00 & 1.00 \\
Rural (=1 if yes) & 0.08 & 0.27 & 0.00 & 1.00 \\
Survey Year & 2010.61 & 2.58 & 2007.00 & 2014.00 \\
\hline
\end{tabular}

Note: the number of observation is 3574

An ordered logit is a version of logistic analysis. The methodology and interpretation of results are similar across both methods except that in the case of an ordered logit the dependent variable contains more than two outcome categories. An ordered logit is distinct from a multinomial logit. In the case of a multinomial logit, there is nothing specific about the ordering of the outcomes. However, with a variable such as change in health, the outcome categories are in a specific order from worst to best outcomes. We need a method which takes account of this characteristic of the dependent variable, and this is why we employ an ordered logit versus the unordered multinomial logit. Logit methods are commonly used in migration research (Chen and Hamori, 2009) and their theoretical bases are well known.

The standard way of estimating an ordered logit model is to assume that the estimated coefficients are the same across all ordered categories. That is, the coefficients that describe the relationship between, the worst health outcome versus all higher categories of health are the same as those that describe the relationship between the worst two health outcomes and all 
higher categories, etc. This is the well-known "proportional odds assumption". However, in many cases assuming proportional odds is inappropriate. It is possible to test the proportional odds assumption ${ }^{3}$. In our ordered logit models, the null of proportional odds was rejected in all cases. We therefore estimated models that did not constrain the coefficients to be equal across all ordered categories ${ }^{4}$.

One interprets the unconstrained coefficients from the various ordered categories as coefficients from a series of binary logit models. For example, if you have three ordered categories A, B and C, the first set of coefficients would be from a model of A vs B $+\mathrm{C}$. The second set would be from a model of $\mathrm{A}+\mathrm{B}$ vs $\mathrm{C}$. That is, you estimate different coefficients for n-1 binary logit models (see Williams, 2005). In our sample, our change in health ordered dependent variable had values ranging from -3 to +1 . Thus, the binary logit models are as follows:

a) (-3) vs $(-2,-1,0,1)$ - very major decline in health

b) $(-3,-2)$ vs $(-1,0,1)$ - major decline in health

c) $(-3,-2,-1)$ vs $(0,1)$ - decline in health

d) $(-3,-2,-1,0)$ vs $(1)-$ decline or no change in health

Unlike OLS, when interpreting any type of logistic analysis, one cannot use the coefficients for magnitudes. The results of a logit are best interpreted when presented in terms of odds ratios. If the odds ratio is greater (less) than one for the "change in health" ordinal dependent variable, then a one-unit increase in the explanatory variable increases (decreases) the likelihood that health will be improved. For a dichotomous explanatory variable like "owns property" the interpretation of the odds ratio is straightforward. For example, an odds ratio value of 2.00 on "owns property" would suggest that if the household does own property $(X=1)$ the likelihood of health improvement would be $200 \%$, whereas an odds ratio of .50 would be interpreted as a $50 \%$ likelihood of worsened health. ${ }^{5}$

Interpreting odds ratios with continuous explanatory variables is more complex. This is because odds ratios are not the same as probabilities. In the case of continuous explanatory variables, odds ratios have a compounding effect. Let us assume that explanatory variable $\mathrm{X}$ ranges from 1 to 5. Suppose a logit on dichotomous dependent variable $\mathrm{Y}$ (e.g. hypertension) results in an odds ratio of 2.00 with respect to explanatory variable $X$. This would mean that the likelihood of $Y=1$ is twice as high for $X=2$ as it is for $X=1$. And the likelihood of $Y=1$ is twice as high for $X=3$ as it is for $X=2$. This compounds over values of $X$ so that the

\footnotetext{
${ }^{3}$ The Stata command for this test is omodel. The test results are available upon request.

${ }^{4}$ The Stata command we used was gologit2. See Williams (2005).

${ }^{5}$ Note that for our dichotomous dependent variables (diabetes and hypertension) an odds ratio greater than 1.00 indicates a worsened health outcome since $\mathrm{Y}=1$ indicates the presence of diabetes or hypertension. Similarly an odds ratio of less than 1.00 indicates an absence of diabetes/hypertension and hence an improved health outcome.
} 
likelihood of $Y=1$ is 16 times as high for $X=5$ as for $X=1$. Thus, it might be tempting to interpret an odds ratio that is just slightly greater than 1.00 (e.g. 1.001) as close to even odds of impacting the dependent variable (e.g. even odds of worsening or improving hypertension). This would be an incorrect conclusion, however, if the continuous explanatory variable has a wide range (e.g. months of cumulative U.S. experience) because of the compounding effect. The compounded effect would be considerable for those who cumulatively spent many months in the United States. Note that because of the interpretive complexities of using odds ratios, we can also generate predicted probabilities of a particular outcome category for marginal changes in a covariate, which we do in the Results section for critical covariates using Stata's margin command.

The Appendices discuss additional analyses. The first appendix contains results from propensity score matched samples. The second appendix discusses results from different formulations of the model. These results (and the main regression results) broadly support the hypotheses presented at the beginning of the paper.

\section{Results}

The results vary significantly based on the type of health and migration measures used in the analysis. The results from the ordered logit on self-reported health are in Tables 2-5. Each table contains results from one of the outcomes for the dependent variable change in health. Odds ratios greater than one represent an improvement in health. The logit results from diabetes and hypertension are contained in Tables 6 and 7, respectively. For the dependent variables in Tables 2-5, an odds ratio greater than one represents a higher likelihood of being diagnosed with a medical condition and can be considered as a worsening of health. There are additional results and a discussion of some robustness checks contained in the Appendices.

The impact of U.S. and domestic migration on health varies based on the type of health measure used for the dependent variable. This is confirmation of the third hypothesis (H3) presented in the paper's introduction. When the subjective, self-reported change in health is used as the dependent variable, domestic and U.S. migration (as measured by the number of trips) appear to have significant negative impacts on health. Cumulative U.S. experience (as measured by the total length of time spent in the U.S.) appears to have a less consistent negative effect on health. In contrast, when the dependent variable is either the objective diabetes or hypertension variable, we find no significant impact of either the number of U.S. or domestic migrations on health, while cumulative migration experience in the United States is a significant indicator of increased hypertension but not diabetes. Interestingly, cumulative U.S. migration experience does become a significant predictor of diabetes (and a strengthened predictor of hypertension) when the logit is run without BMI as an explanatory variable. This 
ORTMEYER, QUINN Health Impacts of Mexico - U.S. Migration

Table 2: Impact of Migration on Likelihood of Very Major Decline in Health

\begin{tabular}{|c|c|c|c|}
\hline & Model 1 & Model 2 & Model 3 \\
\hline Age & $\begin{array}{c}0.83 \\
(-2.27)^{* *}\end{array}$ & $\begin{array}{c}0.84 \\
(-2.25)^{* *}\end{array}$ & $\begin{array}{c}0.83 \\
(-2.30)^{* *}\end{array}$ \\
\hline Age Squared & $\begin{array}{c}1.00 \\
(1.41) \\
\end{array}$ & $\begin{array}{c}1.00 \\
(1.46) \\
\end{array}$ & $\begin{array}{c}1.00 \\
(1.44) \\
\end{array}$ \\
\hline Education & $\begin{array}{l}1.02 \\
(0.4)\end{array}$ & $\begin{array}{c}1.02 \\
(0.51)\end{array}$ & $\begin{array}{c}1.01 \\
(0.37)\end{array}$ \\
\hline Cumulative U.S. Experience & & $\begin{array}{c}0.999 \\
(-0.76) \\
\end{array}$ & $\begin{array}{c}1.00 \\
(0.49) \\
\end{array}$ \\
\hline \# U.S. Migrations & $\begin{array}{c}0.82 \\
(-2.58)^{* * *}\end{array}$ & & $\begin{array}{c}0.79 \\
(-2.35)^{* * *}\end{array}$ \\
\hline \# Domestic Migrations & $\begin{array}{c}0.71 \\
(-3.78)^{* * *}\end{array}$ & $\begin{array}{c}0.71 \\
(-3.84)^{* * *}\end{array}$ & $\begin{array}{c}0.71 \\
(-3.74)^{* * *}\end{array}$ \\
\hline Smoking & $\begin{array}{c}1.44 \\
(0.81) \\
\end{array}$ & $\begin{array}{c}1.52 \\
(0.93) \\
\end{array}$ & $\begin{array}{c}1.41 \\
(0.75) \\
\end{array}$ \\
\hline BMI & $\begin{array}{c}1.04 \\
(1.04) \\
\end{array}$ & $\begin{array}{c}1.04 \\
(1.09) \\
\end{array}$ & $\begin{array}{c}1.03 \\
(0.94) \\
\end{array}$ \\
\hline Own Property & $\begin{array}{c}2.2 \\
(2.22)^{* *}\end{array}$ & $\begin{array}{c}2.17 \\
(2.16)^{* *}\end{array}$ & $\begin{array}{c}2.23 \\
(2.26)^{* *}\end{array}$ \\
\hline Remittances & $\begin{array}{c}0.998 \\
(-0.00) \\
\end{array}$ & $\begin{array}{c}0.83 \\
(-0.49) \\
\end{array}$ & $\begin{array}{c}1.04 \\
(0.09) \\
\end{array}$ \\
\hline \# Doctors & $\begin{array}{c}0.997 \\
(-0.65) \\
\end{array}$ & $\begin{array}{c}0.997 \\
(-0.54)\end{array}$ & $\begin{array}{c}0.997 \\
(-0.61) \\
\end{array}$ \\
\hline Large Urban & $\begin{array}{c}2.41 \\
(1.34) \\
\end{array}$ & $\begin{array}{c}2.37 \\
(1.33) \\
\end{array}$ & $\begin{array}{c}2.37 \\
(1.32) \\
\end{array}$ \\
\hline Small Urban & $\begin{array}{c}5.895 \\
(2.17)^{* *}\end{array}$ & $\begin{array}{c}5.96 \\
(2.19)^{* *}\end{array}$ & $\begin{array}{c}5.77 \\
(2.14)^{* *}\end{array}$ \\
\hline Town & $\begin{array}{c}3.34 \\
(2.77)^{* * *}\end{array}$ & $\begin{array}{c}3.12 \\
(2.62)^{* * *}\end{array}$ & $\begin{array}{c}3.26 \\
(2.71)^{* * *}\end{array}$ \\
\hline Survey Year & $\begin{array}{c}0.91 \\
(-1.88)^{*}\end{array}$ & $\begin{array}{c}0.91 \\
(-1.74)^{*}\end{array}$ & $\begin{array}{c}0.91 \\
(-1.84)^{*}\end{array}$ \\
\hline Chi-Squared (Prob $>0)$ & 0.00 & 0.00 & 0.00 \\
\hline Number of Observations & 3,574 & 3,574 & 3,574 \\
\hline
\end{tabular}

Note: Odds ratios shown with z-statistics in parentheses.

$$
{ }^{*} \mathrm{p}<0.1 ; * * \mathrm{p}<0.05 ; * * * \mathrm{p}<0.01
$$


Review of Economic Analysis 10 (2018) 151-179

Table 3: Impact of Migration on Likelihood of Major Decline in Health

\begin{tabular}{|c|c|c|c|}
\hline & Model 1 & Model 2 & Model 3 \\
\hline Age & $\begin{array}{c}0.91 \\
(-3.75)^{* * *}\end{array}$ & $\begin{array}{c}0.91 \\
(-3.71)^{* * *}\end{array}$ & $\begin{array}{c}0.91 \\
(-3.73)^{* * *}\end{array}$ \\
\hline Age Squared & $\begin{array}{c}1.00 \\
(1.35)\end{array}$ & $\begin{array}{c}1.00 \\
(1.36)\end{array}$ & $\begin{array}{c}1.00 \\
(1.35)\end{array}$ \\
\hline Education & $\begin{array}{c}1.01 \\
(0.56)\end{array}$ & $\begin{array}{c}1.01 \\
(0.66)\end{array}$ & $\begin{array}{c}1.01 \\
(0.58)\end{array}$ \\
\hline Cumulative U.S. Experience & & $\begin{array}{c}0.999 \\
(-1.89)^{*}\end{array}$ & $\begin{array}{c}0.999 \\
(-0.88)\end{array}$ \\
\hline \# U.S. Migrations & $\begin{array}{c}0.92 \\
(-2.50)^{* *}\end{array}$ & & $\begin{array}{c}0.94 \\
(-1.81)^{* *}\end{array}$ \\
\hline \# Domestic Migrations & $\begin{array}{c}0.88 \\
(-2.51)^{* *}\end{array}$ & $\begin{array}{c}0.88 \\
(-2.55)^{* *}\end{array}$ & $\begin{array}{c}0.88 \\
(-2.52)^{* *}\end{array}$ \\
\hline Smoking & $\begin{array}{c}1.04 \\
(0.27) \\
\end{array}$ & $\begin{array}{c}1.05 \\
(0.36) \\
\end{array}$ & $\begin{array}{c}1.05 \\
(0.31) \\
\end{array}$ \\
\hline BMI & $\begin{array}{c}0.99 \\
(-0.93) \\
\end{array}$ & $\begin{array}{c}0.99 \\
(-0.86) \\
\end{array}$ & $\begin{array}{c}0.99 \\
(-0.87) \\
\end{array}$ \\
\hline Own Property & $\begin{array}{c}1.36 \\
(2.12)^{* *}\end{array}$ & $\begin{array}{c}1.33 \\
(1.99)^{* *}\end{array}$ & $\begin{array}{c}1.35 \\
(2.09)^{* *}\end{array}$ \\
\hline Remittances & $\begin{array}{c}0.78 \\
(-1.69)^{*}\end{array}$ & $\begin{array}{c}0.76 \\
(-1.82)^{*}\end{array}$ & $\begin{array}{c}0.79 \\
(-1.62)^{*}\end{array}$ \\
\hline \# Doctors & $\begin{array}{c}1.00 \\
(0.45)\end{array}$ & $\begin{array}{c}1.00 \\
(0.49)\end{array}$ & $\begin{array}{c}1.00 \\
(0.40)\end{array}$ \\
\hline Large Urban & $\begin{array}{c}1.01 \\
(0.03)\end{array}$ & $\begin{array}{c}1.00 \\
(0.00)\end{array}$ & $\begin{array}{c}1.02 \\
(0.06)\end{array}$ \\
\hline Small Urban & $\begin{array}{c}1.17 \\
(0.59)\end{array}$ & $\begin{array}{c}1.15 \\
(0.53) \\
\end{array}$ & $\begin{array}{c}1.17 \\
(0.60)\end{array}$ \\
\hline Town & $\begin{array}{c}1.14 \\
(0.65)\end{array}$ & $\begin{array}{c}1.14 \\
(0.63) \\
\end{array}$ & $\begin{array}{c}1.15 \\
(0.69) \\
\end{array}$ \\
\hline Survey Year & $\begin{array}{c}0.95 \\
(-2.20)^{* *}\end{array}$ & $\begin{array}{c}0.96 \\
(-2.15)^{* *}\end{array}$ & $\begin{array}{c}0.95 \\
(-2.17)^{* *}\end{array}$ \\
\hline Chi-Squared (Prob $>0)$ & 0.00 & 0.00 & 0.00 \\
\hline Number of Observations & 3,574 & 3,574 & 3,574 \\
\hline
\end{tabular}

Note: Odds ratios shown with z-statistics in parentheses.

$* \mathrm{p}<0.1 ; * * \mathrm{p}<0.05 ; * * * \mathrm{p}<0.01$ 
ORTMEYER, QUINN Health Impacts of Mexico - U.S. Migration

Table 4: Impact of Migration on Likelihood of Decline in Health

\begin{tabular}{|c|c|c|c|}
\hline & Model 1 & Model 2 & Model 3 \\
\hline Age & $\begin{array}{c}0.93 \\
(-4.52)^{* * *}\end{array}$ & $\begin{array}{c}0.93 \\
(-4.52)^{* * *}\end{array}$ & $\begin{array}{c}0.93 \\
(-4.49)^{* * *}\end{array}$ \\
\hline Age Squared & $\begin{array}{c}1.00 \\
(1.52)\end{array}$ & $\begin{array}{c}1.00 \\
(1.57)\end{array}$ & $\begin{array}{c}1.00 \\
(1.52)\end{array}$ \\
\hline Education & $\begin{array}{c}0.99 \\
(-0.81)\end{array}$ & $\begin{array}{c}0.99 \\
(-0.74) \\
\end{array}$ & $\begin{array}{c}0.99 \\
(-0.80) \\
\end{array}$ \\
\hline Cumulative U.S. Experience & & $\begin{array}{c}0.998 \\
(-2.96)^{* * *}\end{array}$ & $\begin{array}{c}0.998 \\
(-1.98)^{* *}\end{array}$ \\
\hline \# U.S. Migrations & $\begin{array}{c}0.94 \\
(-2.63)^{* * *}\end{array}$ & & $\begin{array}{c}0.96 \\
(-1.26) \\
\end{array}$ \\
\hline \# Domestic Migrations & $\begin{array}{c}0.88 \\
(-2.88)^{* * *}\end{array}$ & $\begin{array}{c}0.88 \\
(-2.93) * * *\end{array}$ & $\begin{array}{c}0.88 \\
(-2.89)^{* * *}\end{array}$ \\
\hline Smoking & $\begin{array}{c}0.92 \\
(-0.88)\end{array}$ & $\begin{array}{c}0.93 \\
(-0.81)\end{array}$ & $\begin{array}{c}0.93 \\
(-0.83)\end{array}$ \\
\hline BMI & $\begin{array}{c}0.999 \\
(-0.12) \\
\end{array}$ & $\begin{array}{c}0.99995 \\
(-0.01)\end{array}$ & $\begin{array}{l}0.9999 \\
(-0.02) \\
\end{array}$ \\
\hline Own Property & $\begin{array}{c}1.09 \\
(0.91)\end{array}$ & $\begin{array}{c}1.08 \\
(0.79)\end{array}$ & $\begin{array}{c}1.09 \\
(0.88)\end{array}$ \\
\hline Remittances & $\begin{array}{c}0.76 \\
(-2.25)^{* *}\end{array}$ & $\begin{array}{c}0.77 \\
(-2.17)^{* *}\end{array}$ & $\begin{array}{c}0.78 \\
(-2.07)^{* *}\end{array}$ \\
\hline \# Doctors & $\begin{array}{c}1.00 \\
(2.26)^{* *}\end{array}$ & $\begin{array}{c}1.00 \\
(2.19)^{* *}\end{array}$ & $\begin{array}{c}1.00 \\
(2.12)^{* *}\end{array}$ \\
\hline Large Urban & $\begin{array}{c}0.8 \\
(-1.18) \\
\end{array}$ & $\begin{array}{c}0.81 \\
(-1.13)\end{array}$ & $\begin{array}{c}0.81 \\
(-1.12) \\
\end{array}$ \\
\hline Small Urban & $\begin{array}{c}1.05 \\
(0.31) \\
\end{array}$ & $\begin{array}{c}1.05 \\
(0.27) \\
\end{array}$ & $\begin{array}{c}1.05 \\
(0.30) \\
\end{array}$ \\
\hline Town & $\begin{array}{c}1.07 \\
(0.52)\end{array}$ & $\begin{array}{c}1.08 \\
(0.58) \\
\end{array}$ & $\begin{array}{c}1.08 \\
(0.59)\end{array}$ \\
\hline Survey Year & $\begin{array}{c}0.9 \\
(-6.49)^{* * *} \\
\end{array}$ & $\begin{array}{c}0.9 \\
(-6.39)^{* * *} \\
\end{array}$ & $\begin{array}{c}0.9 \\
(-6.37)^{* * *} \\
\end{array}$ \\
\hline Chi-Squared $($ Prob $>0)$ & 0.00 & 0.00 & 0.00 \\
\hline Number of Observations & 3,574 & 3,574 & 3,574 \\
\hline
\end{tabular}

Note: Odds ratios shown with z-statistics in parentheses.

$$
* \mathrm{p}<0.1 ; * * \mathrm{p}<0.05 ; * * * \mathrm{p}<0.01
$$


Table 5: Impact of Migration on Likelihood of Decline or No Change in Health

\begin{tabular}{|c|c|c|c|}
\hline & Model 1 & Model 2 & Model 3 \\
\hline Age & $\begin{array}{c}1.11 \\
(1.10)\end{array}$ & $\begin{array}{c}1.11 \\
(1.09)\end{array}$ & $\begin{array}{c}1.11 \\
(1.08)\end{array}$ \\
\hline Age Squared & $\begin{array}{c}1.00 \\
(-1.50)\end{array}$ & $\begin{array}{c}1.00 \\
(-1.51)\end{array}$ & $\begin{array}{c}1.00 \\
(-1.50)\end{array}$ \\
\hline Education & $\begin{array}{c}0.99 \\
(-0.15)\end{array}$ & $\begin{array}{c}0.99 \\
(-0.14)\end{array}$ & $\begin{array}{c}0.99 \\
(-0.14)\end{array}$ \\
\hline Cumulative U.S. Experience & & $\begin{array}{c}1 \\
(0.70)\end{array}$ & $\begin{array}{c}1 \\
(0.66)\end{array}$ \\
\hline \# U.S. Migrations & $\begin{array}{c}1 \\
(0.05) \\
\end{array}$ & & $\begin{array}{c}0.99 \\
(-0.12) \\
\end{array}$ \\
\hline \# Domestic Migrations & $\begin{array}{c}1.32 \\
(1.94)^{* *}\end{array}$ & $\begin{array}{c}1.33 \\
(1.95)^{* *}\end{array}$ & $\begin{array}{c}1.33 \\
(1.95)^{* *}\end{array}$ \\
\hline Smoking & $\begin{array}{c}0.46 \\
(-1.63)\end{array}$ & $\begin{array}{c}0.45 \\
(-1.67)^{*}\end{array}$ & $\begin{array}{c}0.45 \\
(-1.67)^{*}\end{array}$ \\
\hline BMI & $\begin{array}{c}0.92 \\
(-1.83)^{*}\end{array}$ & $\begin{array}{c}0.92 \\
(-1.86)^{*}\end{array}$ & $\begin{array}{c}0.92 \\
(-1.85)^{*}\end{array}$ \\
\hline Own Property & $\begin{array}{c}1.19 \\
(0.45)\end{array}$ & $\begin{array}{c}1.18 \\
(0.41)\end{array}$ & $\begin{array}{c}1.18 \\
(0.42)\end{array}$ \\
\hline Remittances & $\begin{array}{c}0.58 \\
(-0.72) \\
\end{array}$ & $\begin{array}{c}0.54 \\
(-0.81)\end{array}$ & $\begin{array}{c}0.54 \\
(-0.81)\end{array}$ \\
\hline \# Doctors & $\begin{array}{c}1.00 \\
(0.29)\end{array}$ & $\begin{array}{c}1.00 \\
(0.36)\end{array}$ & $\begin{array}{c}1.00 \\
(0.36)\end{array}$ \\
\hline Large Urban & $\begin{array}{c}903393.4 \\
(0.02)\end{array}$ & $\begin{array}{c}877020.40 \\
(0.02)\end{array}$ & $\begin{array}{c}875909.9 \\
(0.02)\end{array}$ \\
\hline Small Urban & $\begin{array}{c}4351922 \\
(0.02)\end{array}$ & $\begin{array}{c}4432637 \\
(0.02)\end{array}$ & $\begin{array}{c}4433135 \\
(0.02)\end{array}$ \\
\hline Town & $\begin{array}{c}1824667 \\
(0.02)\end{array}$ & $\begin{array}{c}1812796 \\
(0.02)\end{array}$ & $\begin{array}{c}1814078 \\
(0.02)\end{array}$ \\
\hline Survey Year & $\begin{array}{c}0.87 \\
(-1.74)^{*} \\
\end{array}$ & $\begin{array}{c}0.86 \\
(-1.84)^{*} \\
\end{array}$ & $\begin{array}{c}0.86 \\
(-1.83)^{*}\end{array}$ \\
\hline Chi-Squared (Prob $>0)$ & 0.00 & 0.00 & 0.00 \\
\hline Number of Observations & 3,574 & 3,574 & 3,574 \\
\hline
\end{tabular}

Note: Odds ratios shown with z-statistics in parentheses.

$* \mathrm{p}<0.1 ; * * \mathrm{p}<0.05 ; * * * \mathrm{p}<0.01$ 
ORTMEYER, QUINN Health Impacts of Mexico - U.S. Migration

Table 6: Impact of Migration on Likelihood of Diabetes

\begin{tabular}{|c|c|c|c|}
\hline & Model 1 & Model 2 & Model 3 \\
\hline Age & $\begin{array}{c}1.254 \\
(5.90)^{* * *}\end{array}$ & $\begin{array}{c}1.254 \\
(5.87)^{* * *}\end{array}$ & $\begin{array}{c}1.254 \\
(5.87)^{* * *}\end{array}$ \\
\hline Age Squared & $\begin{array}{c}1.00 \\
(4.76)^{* * *}\end{array}$ & $\begin{array}{c}1.00 \\
(4.72)^{* * *}\end{array}$ & $\begin{array}{c}1.00 \\
(4.74)^{* * *}\end{array}$ \\
\hline Education & $\begin{array}{c}0.987 \\
(0.76) \\
\end{array}$ & $\begin{array}{c}0.987 \\
(0.76) \\
\end{array}$ & $\begin{array}{l}0.987 \\
(0.79) \\
\end{array}$ \\
\hline Cumulative U.S. Experience & & $\begin{array}{l}1.001 \\
(1.14)\end{array}$ & $\begin{array}{l}1.001 \\
(1.61)\end{array}$ \\
\hline \# U.S. Migrations & $\begin{array}{l}0.996 \\
(0.12)\end{array}$ & & $\begin{array}{l}0.975 \\
(0.74) \\
\end{array}$ \\
\hline \# Domestic Migrations & $\begin{array}{r}1.039 \\
(0.51) \\
\end{array}$ & $\begin{array}{c}1.038 \\
(0.51) \\
\end{array}$ & $\begin{array}{l}1.039 \\
(0.52) \\
\end{array}$ \\
\hline Smoking & $\begin{array}{c}1.38 \\
(2.46)^{* *}\end{array}$ & $\begin{array}{c}1.372 \\
(2.41)^{* *}\end{array}$ & $\begin{array}{c}1.371 \\
(2.38)^{* *}\end{array}$ \\
\hline BMI & $\begin{array}{c}1.039 \\
(2.60)^{* * *}\end{array}$ & $\begin{array}{c}1.038 \\
(2.53)^{* *}\end{array}$ & $\begin{array}{c}1.038 \\
(2.53)^{* *}\end{array}$ \\
\hline Own Property & $\begin{array}{c}1.351 \\
(1.77)^{*}\end{array}$ & $\begin{array}{c}1.355 \\
(1.86)^{*}\end{array}$ & $\begin{array}{c}1.364 \\
(1.86)^{*}\end{array}$ \\
\hline Remittances & $\begin{array}{c}1.569 \\
(3.59)^{* * *}\end{array}$ & $\begin{array}{c}1.536 \\
(3.42)^{* * *}\end{array}$ & $\begin{array}{c}1.553 \\
(3.44)^{* * *}\end{array}$ \\
\hline \# Doctors & $\begin{array}{c}1.00 \\
(1.09) \\
\end{array}$ & $\begin{array}{c}1.00 \\
(1.28) \\
\end{array}$ & $\begin{array}{l}1.00 \\
(1.2) \\
\end{array}$ \\
\hline Large Urban & $\begin{array}{c}0.967 \\
(0.1) \\
\end{array}$ & $\begin{array}{c}0.95 \\
(0.15) \\
\end{array}$ & $\begin{array}{l}0.955 \\
(0.14) \\
\end{array}$ \\
\hline Small Urban & $\begin{array}{l}1.015 \\
(0.04)\end{array}$ & $\begin{array}{l}1.013 \\
(0.04)\end{array}$ & $\begin{array}{l}1.016 \\
(0.05)\end{array}$ \\
\hline Town & $\begin{array}{l}0.866 \\
(0.43)\end{array}$ & $\begin{array}{c}0.853 \\
(0.48) \\
\end{array}$ & $\begin{array}{l}0.855 \\
(0.47)\end{array}$ \\
\hline Survey Year & $\begin{array}{c}1.039 \\
(1.84)^{*}\end{array}$ & $\begin{array}{c}1.038 \\
(1.87)^{*}\end{array}$ & $\begin{array}{c}1.038 \\
(1.86)^{*} \\
\end{array}$ \\
\hline Chi-Squared (Prob>0) & 0.00 & 0.00 & 0.00 \\
\hline Number of Observations & 3,587 & 3,587 & 3,587 \\
\hline
\end{tabular}

Note: Odds ratios shown with z-statistics in parentheses.

$$
{ }^{*} \mathrm{p}<0.1 ;{ }^{* *} \mathrm{p}<0.05 ;{ }^{* * *} \mathrm{p}<0.01
$$


Review of Economic Analysis 10 (2018) 151-179

Table 7: Impact of Migration on Likelihood of Hypertension

\begin{tabular}{|c|c|c|c|}
\hline & Model 1 & Model 2 & Model 3 \\
\hline Age & $\begin{array}{c}1.115 \\
(4.41)^{* * *}\end{array}$ & $\begin{array}{c}1.115 \\
(4.28)^{* * *}\end{array}$ & $\begin{array}{c}1.115 \\
(4.29)^{* * *}\end{array}$ \\
\hline Age Squared & $\begin{array}{c}1.00 \\
(1.84)^{*}\end{array}$ & $\begin{array}{c}1.00 \\
(1.79)^{*}\end{array}$ & $\begin{array}{c}1.00 \\
(1.79)^{*}\end{array}$ \\
\hline Education & $\begin{array}{c}1.031 \\
(1.86)^{*}\end{array}$ & $\begin{array}{c}1.03 \\
(1.84)^{*}\end{array}$ & $\begin{array}{c}1.031 \\
(1.84)^{*}\end{array}$ \\
\hline Cumulative U.S. Experience & & $\begin{array}{c}1.001 \\
(2.37)^{* *}\end{array}$ & $\begin{array}{c}1.001 \\
(1.86)^{*}\end{array}$ \\
\hline \# U.S. Migrations & $\begin{array}{c}1.05 \\
(1.56) \\
\end{array}$ & & $\begin{array}{l}1.026 \\
(0.80) \\
\end{array}$ \\
\hline \# Domestic Migrations & $\begin{array}{r}1.056 \\
(1.28) \\
\end{array}$ & $\begin{array}{l}1.057 \\
(1.31) \\
\end{array}$ & $\begin{array}{l}1.056 \\
(1.29) \\
\end{array}$ \\
\hline Smoking & $\begin{array}{c}1.49 \\
(3.77)^{* * *}\end{array}$ & $\begin{array}{c}1.476 \\
(3.71)^{* * *}\end{array}$ & $\begin{array}{c}1.479 \\
(3.71)^{* * *}\end{array}$ \\
\hline BMI & $\begin{array}{c}1.09 \\
(9.01)^{* * *}\end{array}$ & $\begin{array}{c}1.089 \\
(8.74)^{* * *}\end{array}$ & $\begin{array}{c}1.089 \\
(8.75)^{* * *}\end{array}$ \\
\hline Own Property & $\begin{array}{l}0.923 \\
(0.50)\end{array}$ & $\begin{array}{l}0.938 \\
(0.41)\end{array}$ & $\begin{array}{l}0.932 \\
(0.45)\end{array}$ \\
\hline Remittances & $\begin{array}{c}1.13 \\
(0.96)\end{array}$ & $\begin{array}{l}1.129 \\
(0.92)\end{array}$ & $\begin{array}{l}1.116 \\
(0.87)\end{array}$ \\
\hline \# Doctors & $\begin{array}{c}1.00 \\
(1.69)^{*}\end{array}$ & $\begin{array}{c}1.00 \\
(1.62)\end{array}$ & $\begin{array}{c}1.00 \\
(1.57)\end{array}$ \\
\hline Large Urban & $\begin{array}{c}1.37 \\
(1.85)^{*}\end{array}$ & $\begin{array}{c}1.35 \\
(1.76)^{*}\end{array}$ & $\begin{array}{c}1.351 \\
(1.73)^{*}\end{array}$ \\
\hline Small Urban & $\begin{array}{r}1.033 \\
(0.09) \\
\end{array}$ & $\begin{array}{c}1.038 \\
(0.10) \\
\end{array}$ & $\begin{array}{l}1.034 \\
(0.09) \\
\end{array}$ \\
\hline Town & $\begin{array}{l}0.829 \\
(1.25)\end{array}$ & $\begin{array}{l}0.818 \\
(1.34)\end{array}$ & $\begin{array}{l}0.816 \\
(1.37)\end{array}$ \\
\hline Survey Year & $\begin{array}{c}1.018 \\
(0.70) \\
\end{array}$ & $\begin{array}{r}1.017 \\
(0.70) \\
\end{array}$ & $\begin{array}{l}1.017 \\
(0.70) \\
\end{array}$ \\
\hline Chi-Squared $($ Prob $>0)$ & 0.00 & 0.00 & 0.00 \\
\hline Number of Observations & 3,587 & 3,587 & 3,587 \\
\hline
\end{tabular}

Note: Odds ratios shown with z-statistics in parentheses.

$* \mathrm{p}<0.1 ; * * \mathrm{p}<0.05 ; * * * \mathrm{p}<0.01$ 


\section{ORTMEYER, QUINN Health Impacts of Mexico - U.S. Migration}

is consistent with a potential positive relationship between time spent in the United States and increased BMI.

Thus, the perception of health worsens with the number of U.S. or domestic trips but is not affected as much by the cumulative time spent in the United States. Perhaps this is due to the stresses of repeatedly leaving home communities, and these crossing stresses causing a perception of a decline in health even though they don't result in actual increases in diabetes of hypertension. Or, the experience of migration may be changing an individual's reference point when measuring their own health. Objective measures of health, on the other hand, are impacted by cumulative time spent in the United States. ${ }^{6}$ This suggests that longer term factors like acculturation (adopting unhealthy lifestyles over time) might be at play here. Or perhaps the longer time spent in the U.S. makes it more likely that these conditions will be diagnosed.

Hypotheses (H1) and (H2) relate to the differential health impacts of domestic vs U.S. migration. Our priors had suggested that the number of U.S. trips should have a more negative affect on health than the number of domestic trips for two reasons. The first is because each U.S. trip is more arduous than each domestic trip. The second is because each U.S. trip adds to the cumulative time spent in the U.S. increasing the likelihood of acculturating to a less healthy lifestyle. Acculturation is less of an issue for trips within Mexico.

The first of the two reasons can be explored by looking at the self-reported change in health regression, since the numbers of U.S. and domestic trips are not significant in the diabetes or hypertension regressions (as noted above). In Figure 1 we use marginal analysis to show the predicted probabilities of different levels of health decline when the number of U.S. trips increases (following the ordinal logit models discussed in the empirical section). ${ }^{7}$ For a single trip the probability of very major decline in health is extremely small $(.5 \%)$, the probability of major decline in health somewhat higher (7.6\%), decline in health (36.9\%) and decline or no change in health the highest at $54.7 \%$. But as the number of trips increase, notice that the decline or no change in health ordinal category's probabilities start to decline and the probabilities of decline or major decline in health increase. At six U.S. trips, the

\footnotetext{
${ }^{6}$ Remember that because cumulative U.S. experience is a continuous variable the impacts on the health measures as expressed by the odds ratios are compounding with time spent in the U.S. (see the discussion in the Empirical Section). So one month in the U.S. will have a very small increased likelihood of worsened health, but years spent in the U.S. could have a considerable impact.

${ }^{7}$ We use Stata's margin command to predict the probabilities of different ordinal levels when the number of U.S. and domestic trips are increased, holding all other variables fixed at their mean values.
} 
predicted probability of decline or no change in health has fallen to $47 \%$, while the probability of decline in health has risen to $41.6 \%$. Thus, as the number of U.S trips increases so does the likelihood of worsened health. Domestic trips exhibit a similar result as is shown in Figure 2. Clearly there is stress associated with moving away from family and communities.

It is surprising that the predicted probabilities of worsened health from the number of domestic trips are slightly higher than those for U.S. trips. We thought domestic trips would have a zero or only slightly negative effect on health (H1). The results suggest the contrary, that domestic trips have as large a negative effect on health as U.S. trips and the odds ratio coefficients on the domestic trips variable are generally smaller and more significant than the U.S. trips odds ratios. Perhaps this is due to patterns within the sample where people who migrate domestically are older and less-healthy to begin with and less able to make the more arduous journey to the U.S. ${ }^{8}$ Appendix A uses treatment effect regressions to test this possibility.

The second reason why a greater number of U.S. trips might have a more negative impact on health than a similar number of domestic trips is the possibility of adopting a less healthy lifestyle as the cumulative time in the U.S increases. This cumulative effect is best examined by looking at the regressions with the objective health measures (diabetes and hypertension), since cumulative time in the U.S.is not significant in the change in health regressions. Figure 3 shows the predicted probability of diabetes and hypertension as the cumulative time in the U.S. increases. Notice that in each case the probability of acquiring diabetes or hypertension increases slightly with the cumulative number of months spent in the U.S. This is particularly evident with hypertension where the probability rises from $12 \%$ after one year to $14.5 \%$ after 10 years.

The trends in health over time also varied based on health measure. There was a clear and significant negative time trend with respect to self-reported health. The more recent the survey year, the more likely an individual is to report a more negative change in health. However, the results on diabetes were weak and on hypertension were insignificant. As the regressions control for the individual's age and other factors, this might suggest a greater awareness and/or concern generally about health issues. Or this might reflect a greater pessimism regarding health. This suggests a potentially fruitful area for future research with a different data set.

\footnotetext{
${ }^{8}$ Note this is different from sample selection bias where certain groups are systematically prevented from being included in the sample. In our sample we have folks who migrated domestically, folks who migrated to the U.S. and folks who didn't migrate at all.
} 
ORTMEYER, QUINN Health Impacts of Mexico - U.S. Migration

Figure 1: Health Impacts of U.S. Trips

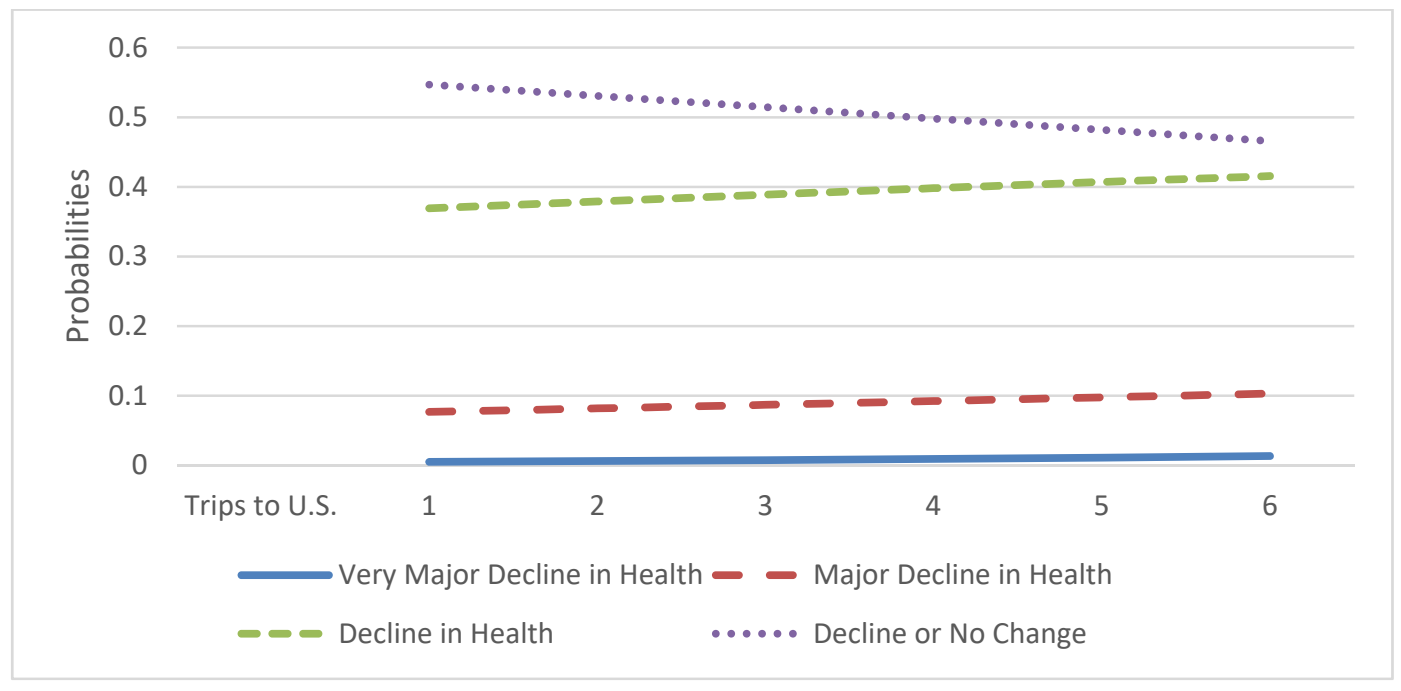

Figure 2: Health Impacts of Domestic Trips

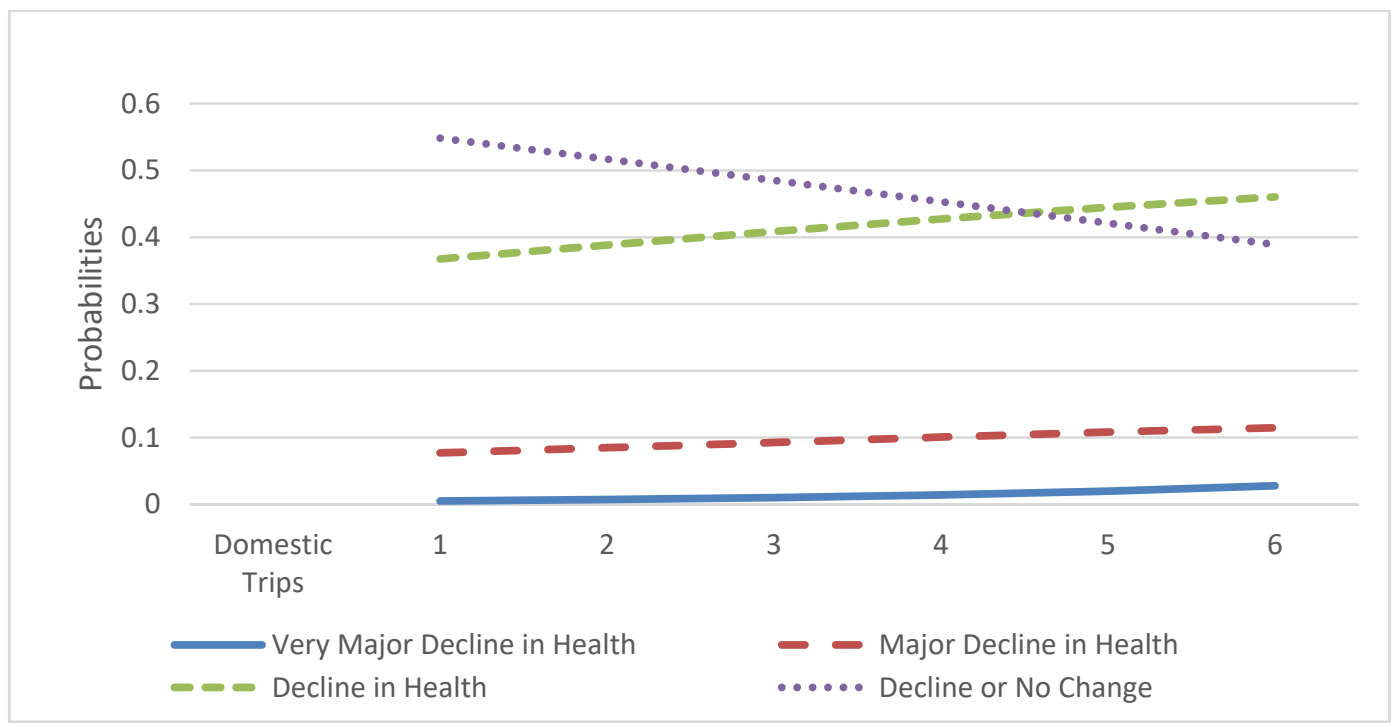

The results from the control variables were as expected from the literature. Age had a significantly negative impact on self-reported health and increased the likelihood of both diabetes and hypertension. Smoking and BMI both significantly increased the likelihood of 
Figure 3: Health Impacts of Cumulative Time in U.S.

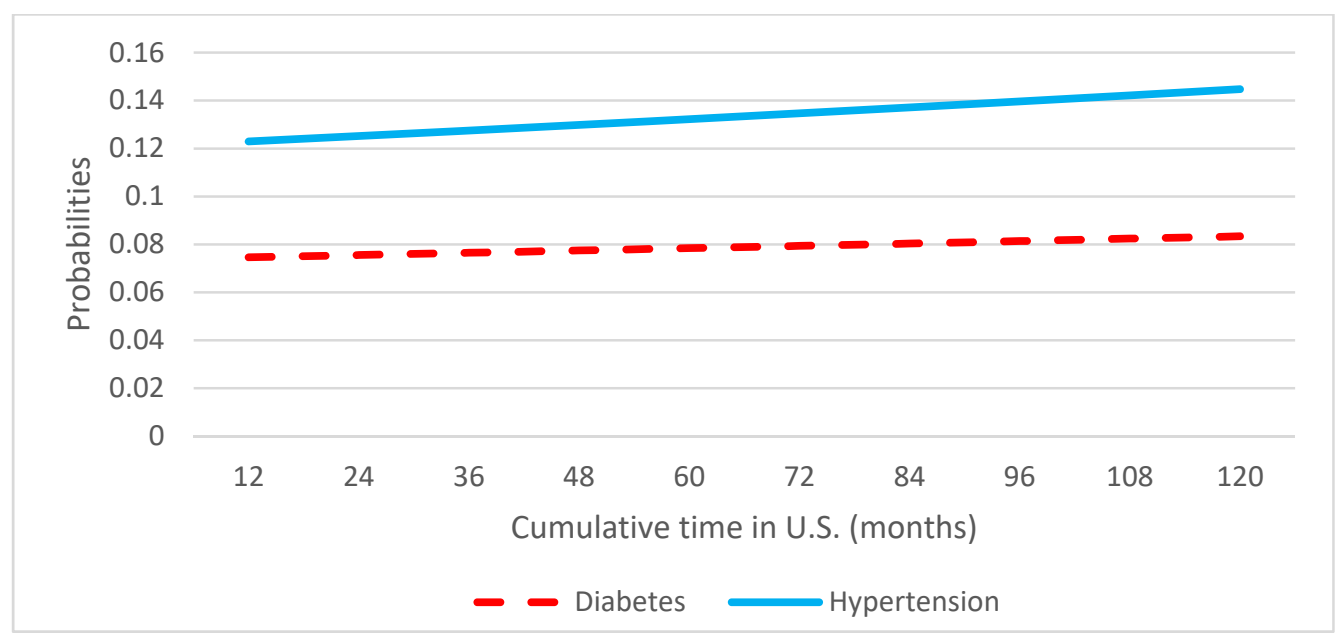

diabetes and hypertension but had no impact on the perception of one's health (as measured by our self-reported change in health variable). Perhaps this suggests that smoking and obesity are not considered important in perceptions of one's health (Balia, 2014; Fletcher, 2014). A household receiving remittances significantly increased the likelihood of diabetes and lowered self-reported health. Owning property also increased the likelihood of diabetes. Property ownership is a component of wealth and remittances supplement household income. The literature has found mixed results with respect to the relationship between income/wealth and diabetes (Fogel, 2004; Wilkinson and Marmot, 2003). In this paper, remittances received by the household may have been sent by household heads (who populate our sample) during their time in the U.S., as opposed to being sent by other family members who migrated. This would result in a decline in their disposable income while in the U.S. and this might negatively impact their health over time. This suggests an interesting avenue to explore with future research.

\section{Conclusions}

With high numbers of people migrating internationally, the issue of immigrant health affects many countries. A significant amount of research has been performed attempting to discern the (often negative) health effects from spending time in the United States. From studying health declines from immigrants who have moved to the United States, this literature has concluded that time spent in the United States causes a deterioration in health. This paper expands on that Literature by testing the impact of international (U.S.) versus domestic 
(within Mexico) migration on health. The MMP data set allows for a unique opportunity to compare the two types of migration and health. This allows for a distinction to be made between the negative health effects from migration (to anywhere outside the household) versus moving specifically to the United States. This is an important distinction to make as migrants could have negative health effects from being away from their home communities even within Mexico. This would overestimate the negative health impact from studies that examine only immigrants within the United States.

The results from this paper are consistent with the hypothesis that time spent in the United States has a negative impact on health. This is a cumulative effect of total time spent rather than the number of trips. Therefore, it is consistent with a theory of acculturation. As it is a cumulative effect, one can observe this for both repeat short-term migrants and long-term movers. The number of trips to the United States also has a strong, consistently negative effect on health regardless of cumulative time spent in the United States. This suggests continued negative crossing effects on the health of migrants.

Another layer of complexity is untangled by utilizing both self-reported and objective health measures. The analyses found significant differences based on the type of measure used, with domestic migration experience having a negative impact on self-reported health but not on objective measures. Interestingly, smoking and high rates of BMI had an impact on diabetes and hypertension rates but not on self-reported health. Overall, this suggests the importance to the literature for testing both subjective and objective measures and for more work in this area to determine the lack of consistency across types of health measures.

In addition to the implications for the literature, this paper is also relevant for policy. As the health effect is from cumulative time spent in the United States (rather than continuous time), this means that short-term Bracero-type guest worker visas could still have significant health implications. If individuals need not stay for a long continuous period in the United States to have a negative health effect, then these repeated short-term immigrants may see health declines as well. This has implications for the government health budgets of Mexico, the U.S. federal government and U.S. states. Results also point to the importance of confronting the problems of smoking and obesity among Mexicans both while in the United States and when back in Mexico. These risk factors can cause problems such as diabetes and hypertension which increase morbidity and costs to the economy. Unfortunately, given the current state of immigration law and political debate in the United States it seems highly unlikely that a major initiative for nutrition education and health screening of Mexican immigrants living in the U.S. will be funded. However, such a program might reduce the 
negative effects of migrating to the United States and lower risk factors that might have longterm health improvements and costs savings for both the U.S. and Mexico.

\section{Appendix A. Additional Results Using Treatment Effect Regressions}

One of the challenges of comparing health outcomes for Mexico-U.S. and intra-Mexico migrants is the issue of selection effects. Immigrants who choose international migration are often different from those who migrate domestically. People who are younger, and often healthier, are the ones who undertake the arduous journey across the U.S. border. Comparing international and domestic migrants' health can be potentially biased if one does not take account of the systematic differences across these samples.

Creating two comparable samples of individuals is commonly done using a propensity score method (Guo and Fraser, 2014; Pan and Bai, 2015). The propensity score methodology matches individuals across two different groups based on several factors. In this case, we are doing two sets of matching. In the first set, we are matching individuals who migrated to the United States with comparable individuals who did not migrate to the U.S. And in the second set, we are matching individuals who migrated within Mexico to individuals who did not migrate within Mexico. This matching is done based on an individual's age and education. Age and education were grouped into six and four different levels, respectively. This was done in order to enable matching across samples, which would be more difficult to achieve using exact number of years. By necessity, the matching is performed on fewer variables than were contained as independent variables in the analyses from the body of the paper. This yields a larger set of usable, complete observations for the treatment effect regressions $(5,053)$ than for the paper's main results $(3,574)$. The propensity score samples passed the balancing test, as reported by Stata's pscore command.

By using the propensity score method, the impact of either U.S. or intra-Mexico migration can be isolated and tested on two samples which share the same characteristics. The regression testing the impact of migration on health is called a treatment effect regression, where the migration is the "treatment". This terminology comes from the method's origins in epidemiological/medical research studies where researchers are interested in testing the impact of taking a specific drug on a person's health. In epidemiological studies testing the impact of a medical treatment or drug on health it is crucial that the samples be properly matched to avoid any confounding factors. This methodology is increasingly being introduced into economics, including in migration studies (Bazillier and Boboc, 2016; Falco and Rotondi, 2016; Mulcahy and Kollamparambil, 2016; Song and Sun, 2016). 
ORTMEYER, QUINN Health Impacts of Mexico - U.S. Migration

Table 8: Treatment Effect Regressions Using

Propensity Score Matched Samples

\begin{tabular}{|l|c||c|}
\hline & $\begin{array}{l}\text { Change in } \\
\text { Health }\end{array}$ & $\begin{array}{l}\text { Current } \\
\text { Health }\end{array}$ \\
\hline \hline U.S. Migration & -0.149 & 0.015 \\
$(-6.00) * * *$ & $(0.71)$ \\
\hline Within-Mexico & -0.139 & 0.230 \\
Migration & $(-4.64) * * *$ & $(0.92)$ \\
\hline
\end{tabular}

Notes: Negative value indicates worse health. Coefficients listed with t-statistics in parentheses.

$* * *$ denotes significance at the .01 percent level. Samples matched based on age and education.

Table 9: Treatment Effect Regressions Using Propensity Score Matched Samples

\begin{tabular}{|l||c|c|c|c|c|c|}
\hline & BMI & Smoking & Hypertension & Diabetes & Heart & Psychological \\
\hline \hline U.S. Migration & 0.156 & 0.041 & 0.023 & 0.008 & 0.016 & 0.032 \\
& $(1.15)$ & $(0.31)$ & $(1.90)^{*}$ & $(0.81)$ & $(2.42)^{* *}$ & $(4.01)^{* * *}$ \\
\hline Within-Mexico & 0.116 & 0.006 & 0.036 & 0.020 & 0.008 & 0.012 \\
Migration & $(0.68)$ & $(0.39)$ & $(2.63)^{* * *}$ & $(1.63)^{*}$ & $(1.22)$ & $(1.42)$ \\
\hline
\end{tabular}

Notes: Positive indicates higher likelihood of condition or higher BMI. Coefficients with t-statistics in parentheses.

$*^{*}{ }^{* *}$, and ${ }^{* *}$ denotes significant at the $.10, .05$, and .01 percent levels, respectively. Samples matched based on age and education.

The results of these regressions are contained in Table 8 and Table 9. In Table 8, the impact of migration is tested on two self-reported health measures: change in health and current health. Table 9 contains the effects of migration on six "objective" health measures. For this table, a positive value indicates a higher likelihood of having the medical condition (or behavior in the case of smoking). These six variables are BMI (body mass index), smoking, hypertension, diabetes, heart disease, and mental illness. The results from both these tables are generally consistent with the analyses contained in the body of the paper. 


\section{Appendix B. Additional Robustness Checks}

Several additional checks were done to ensure robustness of the empirical results. Results are available on request. If there is a significant relationship between U.S. migration and BMI then there is a potential for endogeneity. In order to ensure that this was not driving the results, analyses were run without BMI. As there is a significant literature detailing the negative health effects of undocumented migration we tested a documentation variable (Andreas, 2003; Cornelius, 2001; Eschbach et al, 1999; Eschbach, Mahnken and Goodwin, 2005; Gathmann, 2008; Massey, Durand, and Malone, 2002; Spener, 2001). However, it was consistently insignificant, so it was excluded from the analysis. As most of the trips to the United States were illegal, there was likely not enough variation in the documentation variable to be significant. A series of different dummy variables were also tested. Dummy variables for source state in Mexico, destination state within Mexico, and destination state in the United States were all tested. Another potential concern is the issue of outliers in terms of the migration variables. There is a very small percentage of the sample which have taken a high number of migration trips. The exclusion of these outliers did not impact the results. Analyses were also run controlling for unskilled versus skilled workers and results were robust.

\section{References}

Ahmed, N, (2005), Intergenerational Impact of Immigrants' Selection and Assimilation on Health Outcomes of Children, Analytical Studies Branch Research Paper No.247. Family and Labour Studies Division, Statistics Canada.

Andreas, P, (2003), A Tale of Two Borders: The U.S.-Mexico and U.S. Canada Lines After 9-11, Center for Comparative Immigration Studies Working Paper 77, University of California, San Diego.

Antecol, H., and K. Bedard, (2006), Unhealthy Assimilation: Why do Immigrants Converge to American Health Status Levels, Demography, 43, 337-360.

Arcia, E., Skinner, M., Bailey, D., \& Correa, V. (2001), Models of acculturation and health behaviors among Latino immigrants to the U,, Social Science \& Medicine, 53,41-53.

Arenas, E., Goldman, N., Pebley, A.R., and G. Teruel, (2015), Return Migration to Mexico: Does Health Matter?, Demography, 52(6), 1853-1868.

Balia, S, (2014), Survival Expectations, Subjective Health and Smoking: Evidence from SHARE, Empirical Economics, 47(2), 753-80. 
ORTMEYER, QUINN Health Impacts of Mexico - U.S. Migration

Bazillier, R. and C. Boboc. (2016), Labour Migration as a Way to Escape from Employment Vulnerability? Evidence from the European Union, Applied Economics Letters, 23(16-18), 1149-1152.

Biddle, N., Kennedy, S., and J.T. McDonald, (2007), Health Assimilation patterns amongst Australian Immigrants, Economic Record, 83, 16-30.

Black, S. A., \& Markides, K. S, (1993), Acculturation and alcohol consumption in Puerto Rican, Cuban-American, and Mexican-American Women in the United States, American Journal of Public Health, 83,890-893.

Bzostek, S., Goldman, N., and A. Pebley, (2007), Why Do Hispanics Report Poor Health?, Social Science and Medicine, 65(5), 990-1003.

Center for Disease Control and Prevention (CDC), (2012), Crude and Age-Adjusted Percentage of Civilian, Non-institutionalized Adults with Diagnosed Diabetes, United States,1980-2010, Accessed online at www.cdc.gov/diabetes/statistics/prev/nationa/figageadult.htm.

Chen, G., and S. Hamori, (2009), An Empirical Analysis of Chinese Rural Labour Migration Using a Multinomial Logit Model, Applied Econometrics and International Development, 9(1), 177-186.

Chiswick, B.R., Lee, Y.L., and P.W. Miller, (2008), Immigrant Selection Systems and immigrant health, Contemporary Economic Policy, 26, 555-578.

Cobas, J. A., Balcazar, H., Benin, M. B., Keith, V. M., \& Chong, Y, (1996), Acculturation and Low-Birthweight Infants Among Latino Women, American Journal of Public Health, 86,394-396.

Cornelius, W.A., (2001), Death at the Border: Efficacy and Unintended Consequences of U.S. Immigration Control Policy, Population and Development Review 27 (December), 661685.

Deri, C., (2003), Understanding the 'Healthy Immigrant Effect' in Canada., Working paper 0502E. Department of Economics, University of Ottawa, Ontario, Canada. Available online at http://www. socialsciences.uottawa.ca/eco/pdf/cahiers/0502E.pdf.

Dolfin, S., and G. Genicot, (2010), What Do Networks Do? The Role of Networks on Migration and 'Coyote' Use, Review of Development Economics, 14(2), 343-359.

Doytch, N., Dave, D.M., and I.R. Kelly, (2016), Global Evidence on Obesity and Related Outcomes: An Overview of Prevalence, Trends, and Determinants, Eastern Economic Journal, 42(1), 7-28.

Edwards, J.R, (2010), The Medicaid Costs of Legalizing Illegal Aliens, Center for Immigration Studies Memorandum, Accessed online at www.cis.org. 
Eschbach, K., Hagan, J., Rodriguez, N., Hernandez-Leon, R. and S. Bailey, (1999), Death at the Border, International Migration Review 33 (2), 430-454.

Eschbach, K., J.D. Mahnken, and J.S. Goodwin, (2005), Neighborhood composition and incidence of cancer among Hispanics in the United States, Cancer, 103(5),1036-1044.

Falco, C. and V. Rotondi, (2016), The Less Extreme, the More You Leave: Radical Islam and Willingness to Migrate, World Development, 88, 122-133.

Finch, B.K., Hummer, R.A., Reindl, M., and W.A. Vega, (2002), Validity of Self-rated Health among Latino(a)s, American Journal of Epidemiology, 155(8), 755-759.

Fletcher, J.M, (2014), The Interplay between Gender, Race and Weight Status: Self Perceptions and Social Consequences, Economics and Human Biology, 14, 79-91.

Fogel, R.W. (2004), Health, Nutrition and Economic Growth, Economic Development and Cultural Change, 52, 643-658.

Frisbie, W.P., Cho, Y., and R.A. Hummer, (2001), Immigration and the Health of Asian and Pacific Islander Adults in the United States, American Journal of Epidemiology, 153, 372-380.

Gathmann, C. (2008), Effects of Enforcement on Illegal Markets: Evidence from Migrant Smuggling along the Southwestern Border, Journal of Public Economics, 92, 1926-1941.

Guendelman, S., and B. Abrams, (1994), Dietary Intake Among Mexican-American Women: Generational Differences and a Comparison with White Non-Hispanic Women, American Journal of Public Health, 85, 20-25.

Guo, S. and M.W. Fraser, (2014), Propensity Score Analysis: Statistical Methods and Applications (Advanced Quantitative Techniques in the Social Sciences), Sage Publications, Thousand Oaks, CA.

Hamilton, L.S. (2003), Statistics with Stata, Duxbury/Thomson Learning. Pacific Grove, CA.

Hummer, R. A., Rogers, R. G., Amir, S. H., Forbes, D., and Frisbie, W. P. (2000), Adult Mortality Differentials Among Hispanic Subgroups and Non-Hispanic Whites, Social Science Quarterly, 81, 459-476.

Inkpen, C. (2014), 7 Facts about World Migration, Pew Research Center. Accessed online 9/10/2015 at www.pewresearch.org.

International Diabetes Federation (IDF), (2014), IDF Diabetes Atlas, $6^{\text {th }}$ edition, accessed online 9/9/2015 at http://www.idf.org/diabetesatlas.

Jasso, G; Massey, D; Rosenzweig, M., and J. Smith, (2004), Immigrant Health: Selectivity and Acculturation, Institute for Fiscal Studies, IFS Working Papers: W04/23.

Jasso, G; Massey, D; Rosenzweig, M., and J. Smith, (2005), Immigration, Health, and New York City: Early Results Based on the U.S. New Immigrant Cohort of 2003, Federal Reserve Bank of New York Economic Policy Review, 11, 127-151. 
Kijima, Y. and H. Gonzalez-Ramirez, (2012), Has the Program 3x1 for Migrants Contributed to Community Development in Mexico? Evidence from Panel Data of 2000 and 2005, Review of Development Economics, 16(2), 291-304.

LeClere, F.B., Rogers, R.G., and K.D. Peters, (1997), Ethnicity and Mortality in the United States: Individual and Community Correlates, Social Forces, 76, 169-198.

Li, J., and R.A. Hummer, (2015), The Relationship between Duration of U.S. Residence, Educational Attainment, and Adult Health among Asian Immigrants, Population Research and Policy Review, 34,49-76.

Markides, K. S., and K. Eschbach, (2005), Aging, Migration, and Mortality: Current Status of Research on the Hispanic Paradox, Journals of Gerontology: Series B, 60(2), S68-S75.

Markides, K.S., Krause, N. and C.F. Mendes de Leon, (1988), Acculturation and alcohol consumption among Mexican Americans: A three generations study, American Journal of Public Health, 78,1178-1181.

Marmot, M.G., Adelstein, A.M. and L. Bulusu, (1984), Lessons from the Study of Immigrant Mortality, Lancet, 30, 1455-1457.

Massey, Douglas S., Jorge Durand and Nolan J. Malone, (2002), Beyond Smoke and Mirrors:Mexican Immigration in an Era of Free Trade, New York: Russell Sage Foundation.

McDonald, J.T. and S. Kennedy, (2004), Insights into the 'Healthy Immigrant Effect': Health Status and Health Service Use of Immigrants to Canada, Social Science and Medicine 59,1613-27.

Mexican Migration Project (MMP), (2015), Collected by Princeton University and the University of Guadalajara. Data files and codebooks accessed at http://mmp.opr.princeton.edu/.

Mohanty, S.A., Woolhandler, S., Himmelstein, S.P., Carrasquillo, O., and D.H. Bor, (2005), Health Care Expenditures of Immigrants in the United States: A Nationally Representative Analysis, American Journal of Public Health, 95.

Molina, T. (2016), Reporting Heterogeneity and Health Disparities across Gender and Education Levels: Evidence from Four Countries, Demography, 53(2), 295-323.

Mulcahy, K. and U. Kollamparambil, (2016), The Impact of Rural-Urban Migration on Subjective Well-Being in South Africa, Journal of Development Studies, 52(9), 13571371. 
OECD, (2015), OECD Health Statistics 2015; Country Note: How does Health Spending in Mexico Compare?, Accessed online at oecd.org.

Palloni, A. and E. Arias, (2004), Paradox Lost: Explaining the Hispanic Adult Mortality Advantage, Demography, 41, 385-415.

Pan, W. and H. Bai, (2015), Propensity Score Analysis: Fundamentals and Developments, Guilford Press, New York, New York.

Passel, J., Cohn, D., and A. Gonzalez-Barrera, (2012), Net Migration from Mexico Falls to Zero - and Perhaps Less, Pew Research Center. Accessed March 2013 at www.pewhispanic.org.

Reyes, B.I. (2001), Immigrant Trip Duration: The Case of Immigrants from Western Mexico, International Migration Review, 35,1185-1204.

Riosmena, F., Wong, R., and A. Palloni, (2013), Migration selection, protection, and Acculturation in Health: A Binational Perspective on Older Adults, Demography. 50(3),1039-64.

Seuring, T., Goryakin, Y., and M. Suhrcke, (2015), The Impact of Diabetes on Employment in Mexico, Economics and Human Biology, 18, 85-100.

Song, Y. and W. Sun, (2016), Health Consequences of Rural-To-Urban Migration: Evidence from Panel Data in China, Health Economics, 25(10), 1252-1267.

Spener, D. (2001), Smuggling Mexican Migrants Through South Texas: Challenges Posed by Operation Rio Grande, Global Human Smuggling in Comparative Perspective, The Johns Hopkins University Press, Baltimore, MD.

Teitler, J. O., Hutto, N., \& N.E. Reichman, (2012), Birthweight of children of immigrants by maternal duration of residence in the United States, Social Science \& Medicine, 75, 459468.

Tong, Y., and M. Piotrowski, (2012), Migration and Health Aelectivity in the Context of Internal Migration in China, 1997-2009, Population Research and Policy Review, 31,497543.

Turro, C.M. and I.T. Elo, (2008), The Impact of Salmon Bias on the Hispanic Mortality Advantage: New Evidence from Social Security Data, Population Research and Policy Review, 27, 515-530.

Wilkinson, R. and M. Marmot, (2003), The Social Determinants of Health: The Solid Facts, $2^{\text {nd }}$ edition, World Health Organization Europe, Copenhagen, Denmark.

Williams, Richard, (2005), Gologit2: A Program for Generalized Logistic Regression/Partial Proportional Odds Models for Ordinal Dependent Variables, Stata manual accessed at www.stata.com/meeting/4nasug/gologit2.pdf. 
ORTMEYER, QUINN Health Impacts of Mexico - U.S. Migration

World Bank, (2015), Seguro Popular: Health Coverage for All in Mexico, Accessed online at www.worldbank.org.

World Bank, (2018), World Development Indicators, Accessed online at www.worldbank.org.

Zsembik, B.A, and Fennell, D. (2005), Ethnic variation in health and the determinants of health among Latinos, Social Science and Medicine, 61(1), 53-63. 